\title{
Minimally invasive surgery for early stage lung cancers: satisfactory, but we can do better
}

\author{
Dominique Gossot
}

Thoracic Department, Curie-Montsouris Thoracic Institute, Institut Mutualiste Montsouris, Paris, France

Correspondence to: Dominique Gossot. Thoracic Department, Curie-Montsouris Thoracic Institute, Institut Mutualiste Montsouris, 42 bd Jourdan, F-75014 Paris, France. Email: dominique.gossot@imm.fr.

Provenance: This is an invited Editorial commissioned by Section Editor Dr. Song Xu, MD, PhD (Department of Lung Cancer Surgery, Tianjin Medical University General Hospital; Tianjin Key Laboratory of Lung Cancer Metastasis and Tumor Microenvironment, Lung Cancer Institute, Tianjin, China).

Comment on: Boffa DJ, Kosinski AS, Furnary AP, et al. Minimally Invasive Lung Cancer Surgery Performed by Thoracic Surgeons as Effective as Thoracotomy. J Clin Oncol 2018;36:2378-85.

Submitted Aug 01, 2018. Accepted for publication Oct 30, 2018.

doi: $10.21037 / \mathrm{atm} .2018 .10 .74$

View this article at: http://dx.doi.org/10.21037/atm.2018.10.74

Since the first major pulmonary resections using closed chest surgery, reported 25 years ago (1), the attitude of the surgical and oncology community has changed substantially. Not so long ago, an editorial stated the following sentence: We can no longer ignore the accumulating evidence of these recent reports that suggest VATS lobectomy is inferior oncologically to open lobectomy for clinical stage I lung cancer (2). We have gradually moved from a strong opposition $(3,4)$ to an acceptance of minimally invasive techniques by a large part of the surgical community. The first step in this process came in 2007 with North American large series (5). At the same time, the American College of Chest Physicians (ACCP) updated its guidelines for nonsmall cell lung cancers (NSCLC) by stating that minimally invasive techniques were an acceptable alternative to open chest surgery (6). A further milestone was reached in 2013, again with the ACCP guidelines which this time recommended that minimally invasive techniques should be preferred for early stage tumors (7). In 2018, the penetration rate of these techniques varies from $20 \%$ to $80 \%$ depending on the country and the center (rates of more than $70 \%$ are often related to a center effect). On average, depending on the country, the rate of use of videoassisted techniques (VATS) is around $40 \%$. Surgeons who continue to treat early-stage tumors by thoracotomy, i.e., the remaining $60 \%$, claim these techniques are less safe, that it has not been demonstrated whether survival is equivalent to that of traditional techniques and, above all, that radical lymph node dissection cannot reach the same radicality $(2,8)$.

The interest and merit of the publication of Boffa et al. is to make an important contribution to the debate based on a very large series of stage I NSCLCs operated by thoracotomy (4,448 patients) and thoracoscopy $(6,149$ patients), from a registry containing only certified thoracic surgeons (9). The study shows two findings: four-year survival is equivalent and even slightly higher in the thoracoscopy group $(68.6 \%$ versus $64.8 \% ; \mathrm{P}=0.003)$, despite a significantly higher rate of upstaging in the thoracotomy group $(14.6 \%$ versus $11 \%, \mathrm{P}<0.001)$. The survival rate is equivalent to ours (10) and to other studies (11). Furthermore, the study shows that there is no significant difference in perioperative mortality. These results lead Donington, who signs the editorial accompanying the article to write that thoracotomy to treat stage I tumors is outdated (12).

The fact that survival is equivalent in the two groups, while lymph node clearance seems less complete by thoracoscopy than by thoracotomy, can lead to two different interpretations: (I) radical lymph node dissection is eventually not a fundamental factor in patient survival or (II) survival in the thoracoscopy group would be even better if lymph node dissection were more radical. Indeed, Boffa et al. emphasize the fact that incomplete lymph node dissection poses the two following problems: it leaves tumor 
tissue in place and it ignores lymph node metastases that would have required adjuvant chemotherapy. We can also suggest a third concern: the survival of the thoracoscopy group is probably deteriorated by the fact that N0 patients are actually N2. Yet, several studies have shown that it is possible to perform satisfactory node dissection via thoracoscopy (13) although there is a learning curve (14).

The problem of incomplete lymph node clearance illustrates the weaknesses of this type of multicentric studies, despite the quality of the statistical work and the consideration of a large number of variables, as well as the measures taken to reduce study bias. In all the variables analyzed by Boffa et al., only one of them relates to surgery, i.e., the annual volume of lobectomy (this is the volume per center and not per surgeon). The recently published article on the survival of patients operated on for stage I NSCLC by lobectomy or sublobar resection (SLR) underlines this concern (15). In this study, the increased risk of recurrence was $39 \%$, which is worrying. But the vast majority of SLR were actually wedge resections-which we know are not oncological resections-the margins of resection were invaded in $6 \%$ of cases and the average number of lymph nodes removed was only 1 . Similarly, in the article of Boffa et al. some data raise questions: an invaded margin rate of $3 \%$ (whereas all NSCLC were stage I) and a rate of upstaging significantly lower than that of patients operated on by thoracotomy. This shows that even for certified thoracic surgeons, technical progresses must be made. In a way, if this study demonstrates that the survival of the thoracoscopy group is equivalent to that of the thoracotomy group, one might wonder if it could not be even better. Despite the sophistication of the statistical analysis, studies based on registries and databases, even with large numbers of patients—as is the case in the Boffa et al. study-suffer from the following limitation: they only reflect a situation at the moment $T$ and ignore the surgeons' ability to progress and to find solutions. For example, the study by Licht et al. on lymph node dissection, based on the Danish registry, concluded that the rate of upstaging by thoracoscopy was much lower compared to thoracotomy (8). The results were right and the conclusion was probably adequate at the time of the study, i.e., 2013. However, any visitor to an expert center may observe that thoracoscopic $\mathrm{LN}$ dissection is equivalent, if not superior, to open LN dissection. We thus have 2 choices: either comply with the conclusions of these studies, or seek solutions to do as well or better with VATS as with open surgery.

The open chest and closed chest approaches differ in one fundamental aspect: the majority of thoracic surgeons perform an open chest lobectomy in more or less the same way, because the teaching has been more or less identical. On the other hand, closed chest lobectomy techniques are extremely diverse and variable (16), not only between centers, but even between surgeons in the same institution. Among the many differences are: the use or not of a robot, a various number of ports (from one to five), very different imaging systems and instrumentation, from the most rudimentary to the most sophisticated, etc. In 2013, Douglas Wood asked the question in an editorial "What is most important in improving outcomes after pulmonary lobectomy: the surgeon or the approach?” (17). There are many indicators that this question is still relevant.

The competence and skills of the thoracic surgeon in video-assisted techniques could be a crucial issue in the coming years due to the evolution towards sublobar resections (SLR) to treat an increasing number of early stage tumors. It is indeed demonstrated and accepted that the benefit of SLR is maximum when the procedure is done by VATS. But some segmentectomies, when performed this way can be complex and challenging and require not only technical skills but also technological refinements. It is likely that not all thoracic surgeons will be equal in this evolution.

After a phase of skepticism towards minimally invasive techniques, we suddenly entered a phase of rapid development that was not always under control (18). We must now invest a time of maturity, which is one of thoughtful technical and technological development, aiming at improving our results. If surgeons do not, they expose themselves to creating a situation they fear, that is, the development of expert centers, as illustrated by the conclusion of the editorial by Donington: "Patients, pulmonologists and oncologists should seek out surgeons who can provide this level of expertise" (12).

\section{Acknowledgements}

None.

\section{Footnote}

Conflicts of Interest: The author has no conflicts of interest to declare.

\section{References}

1. Walker WS, Carnochan FM, Pugh GC. Thoracoscopic 
pulmonary lobectomy: early operative experience and preliminary clinical results. J Thorac Cardiovasc Surg 1993;106:1111-7.

2. Mathisen DJ. Is Video-Assisted Thoracoscopic Lobectomy Inferior to Open Lobectomy Oncologically? Ann Thorac Surg 2013;96:755-6.

3. Yim AP. Video-Assisted Thoracic Lung Surgery: Is There a Barrier to Widespread Adoption? Ann Thorac Surg 2010;89:S2112-3.

4. Nomori H, Horio H, Naruke T, et al. What is the advantage of a thoracoscopic lobectomy over a limited thoracotomy procedure for lung cancer surgery? Ann Thorac Surg 2001;72:879-84.

5. Onaitis MW, Petersen RP, Balderson SS, et al.

Thoracoscopic lobectomy is a safe and versatile procedure: experience with 500 consecutive patients. Ann Surg 2006;244:420-5.

6. Scott WJ, Howington J, Feigenberg S, et al. Treatment of non-small cell lung cancer stage I and stage II: ACCP evidence-based clinical practice guidelines (2nd edition). Chest 2007;132:234-42.

7. Howington J, Blum M, Chang A, et al. Treatment of stage I and II non-small cell lung cancer: Diagnosis and management of lung cancer, 3rd ed: American College of Chest Physicians evidence-based clinical practice guidelines. Chest 2013;143:278S-313S.

8. Licht PB, Jørgensen OD, Ladegaard L, et al. A National Study of Nodal Upstaging After Thoracoscopic Versus Open Lobectomy for Clinical Stage I Lung Cancer. Ann Thorac Surg 2013;96:943-9; discussion 949-50.

9. Boffa DJ, Kosinski AS, Furnary AP, et al. Minimally Invasive Lung Cancer Surgery Performed by Thoracic Surgeons as Effective as Thoracotomy. J Clin Oncol

Cite this article as: Gossot D. Minimally invasive surgery for early stage lung cancers: satisfactory, but we can do better. Ann Transl Med 2018;6(Suppl 1):S86. doi: 10.21037/atm.2018.10.74
2018;36:2378-85.

10. Lutz JA, Seguin-Givelet A, Grigoroiu M, et al. Oncological results of full thoracoscopic major pulmonary resections for clinical Stage I non-small-cell lung cancer. Eur J Cardiothorac Surg 2018. [Epub ahead of print].

11. Paul S, Isaacs A, Treasure T, et al. Long term survival with thoracoscopic versus open lobectomy: propensity matched comparative analysis using SEER-Medicare database. BMJ 2014;349:g5575.

12. Donington JS. Thoracotomy for Stage I Lung Cancer Resections: A Procedure Past Its Time. J Clin Oncol 2018;36:2361-2.

13. Ramos R, Girard P, Masuet C, et al. Mediastinal lymph node dissection in early-stage non-small cell lung cancer: totally thoracoscopic vs thoracotomy. Eur J Cardiothorac Surg 2012;41:1342-8; discussion 1348.

14. Boffa DJ, Kosinski AS, Paul S, et al. Lymph Node Evaluation by Open or Video-Assisted Approaches in 11,500 Anatomic Lung Cancer Resections. Ann Thorac Surg 2012;94:347-53.

15. Subramanian M, McMurry T, Meyers B, et al. Long-Term Results for Clinical Stage IA Lung Cancer- Comparing Lobectomy and Sublobar Resection. Ann Thorac Surg 2018;106:375-81.

16. Decaluwé H. One, two, three or four ports... does it matter? Priorities in lung cancer surgery. J Thorac Dis 2016;8:E1704-8.

17. Wood DE. What is most important in improving outcomes after pulmonary lobectomy: the surgeon or the approach? Eur J Cardiothorac Surg 2013;43:817-9.

18. Perna V, Carvajal A, Torrecilla J, et al. Scientific rigour must come first. Eur J Cardiothorac Surg 2017;51:397. 